\title{
EDUCANDO PARA TRANSGREDIR: REFLEXÕES SOBRE O ENSINO CRÍTICO DE LÍNGUAS ESTRANGEIRAS/INGLÊS ${ }^{* *}$
}

\author{
TEACHING TO TRANSGRESS: REFLECTIONS \\ ON CRITICAL FOREIGN LANGUAGE/ENGLISH TEACHING
}

\section{Marco Túlio de Urzêda-Freitas*}

\section{RESUMO}

Neste texto, compartilho algumas reflexões sobre o meu trabalho com o ensino crítico de línguas estrangeiras/inglês no Centro de Línguas da Universidade Federal de Goiás. Teoricamente fundamentado nos pressupostos da Pedagogia Crítica (FREIRE, 2006), dos Estudos Culturais (SILVA, 2007), da Teoria Racial Crítica (FERREIRA, 2006), dos Estudos/ Pedagogias Feministas (LOURO, 1997) e da Linguística Aplicada Crítica (PENNYCOOK, 1998, 2001), procuro relacionar o construto pedagogia como transgressão (HOOKS, 1994; PENNYCOOK, 2006) ao ensino de línguas estrangeiras/inglês. Os dados apresentados mostram que o ensino crítico desencadeia muitos conflitos na sala de aula de língua inglesa, mas também evidenciam a sua relevância para o desenvolvimento crítico, linguístico e comunicativo dos(as) alunos(as) e para a formação crítica de professores(as).

Palavras-chave: ensino crítico de línguas estrangeiras/inglês; Linguística Aplicada Crítica; pedagogia como transgressão.

\section{ABSTRACT}

In this text, I share some reflections of my work with critical foreign language/English teaching at the Centro de Linguas of the Universidade Federal de Goiás. Theoretically supported by the premises of Critical Pedagogy (FREIRE, 2006), Cultural Studies (SILVA, 2007), Critical Racial Theory (FERREIRA, 2006), Feminist Studies/Pedagogies (LOURO,

UFG, Goiânia (GO), Brasil. Professor auxiliar da Faculdade de Letras/PGLL/UFG. <marcotulioufcultura@gmail.com>.

** Este artigo é fruto das profícuas discussões realizadas com a minha então supervisora do Centro de Línguas e atualmente orientadora de mestrado, Rosane Rocha Pessoa, professora associada da Faculdade de Letras da Universidade Federal de Goiás. Agradeço a ela e às professoras Camila Leopoldina Batista dos Santos, Luciane Guimarães de Paula, Nilvânia Damas Silva Lima, Paula de Almeida Silva e Viviane Pires Viana Silvestre pela cuidadosa leitura do texto e pelas contribuições feitas para a produção da versão final. 
1997) and Critical Applied Linguistics (PENNYCOOK, 1998, 2001), I seek to relate the construct pedagogy as transgression (HOOKS, 1994; PENNYCOOK, 2006) to foreign language/English teaching. The data presented show that critical teaching triggers many conflicts in the English language classroom, but they also demonstrate its relevance for the students' critical, linguistic, and communicative improvement, and for the teacher's critical education.

Keywords: critical foreign language/English teaching; Critical Applied Linguistics; pedagogy as transgression.

Com todas as suas limitações, a sala de aula continua sendo um lugar de possibilidades. E, nesse campo de possibilidades, nós [professores/as] temos a chance de trabalhar pela liberdade, de exigir de nós mesmos/as e de nossos/ as colegas uma abertura de espírito e de coração que nos permita encarar a realidade, imaginando, coletivamente, caminhos para nos mover além das fronteiras, para transgredir.

(HOOKS, 1994, p. 207, tradução minha)

\section{CONSIDERAÇÕES INICIAIS}

Neste trabalho, baseio-me no construto pedagogia como transgressão (HOOKS, 1994; PENNYCOOK, 2006) para discutir as características e as consequências do ensino crítico de línguas estrangeiras/inglês no Centro de Línguas ${ }^{1}$ da Universidade Federal de Goiás (doravante UFG). Assim sendo, gostaria de dar início à discussão por meio de três questionamentos: O que significa educar para transgredir? Qual é o lugar da transgressão no campo de estudos críticos em Linguística Aplicada? Como as teorias transgressivas podem colaborar com a promoção de uma abordagem mais holística e politizada para o ensino de línguas estrangeiras/inglês?

Ao definir a educação como um ato performativo, hooks² (1994) afirma que, na condição de professores(as), temos a chance de transgredir os limites da sala de aula para promover mudanças, intervenções e trocas espontâneas de experiências

1. O Centro de Linguas é um Projeto de Extensão da Faculdade de Letras da Universidade Federal de Goiás, criado em 1995, que tem por objetivos: oferecer cursos de línguas estrangeiras e de língua portuguesa para a comunidade acadêmica (professores/as, alunos/as e demais funcionários/as) e para a comunidade geral da grande Goiânia e das cidades circunvizinhas; propiciar um campo de pesquisa para alunos/as da graduação e da pós-graduação da Faculdade de Letras; e servir como campo de estágio para os/as alunos/as das habilitações em língua estrangeira e língua portuguesa do curso de Letras.

2. Mantenho, neste texto, o formato requisitado pela autora, que assina as suas obras em minúsculo alegando que ela não se reduz a um nome. 
e de conhecimento. Por sua vez, tal concepção nos possibilita pensar o ensino de línguas estrangeiras (doravante LE) como transgressão. De acordo com Pennycook (2006), o termo transgressivo pode ser utilizado tanto para demarcar os instrumentos políticos e epistemológicos que visam romper as fronteiras do pensamento e da política tradicionais quanto para pensar o que não deveria ser pensado e fazer o que não deveria ser feito. Com base nas reflexões de hooks (1994), o autor sugere que transgredir significa "opor, resistir e cruzar os limites opressores da dominação pela raça, gênero e classe", o que nos permite construir a imagem "de professores que transgridem os limites normais da pedagogia e ensinam seus próprios alunos a transgredir: a pedagogia como transgressão" (PENNYCOOK, 2006, p. 75).

$\mathrm{Na}$ seara do ensino de LE/inglês, que opera sob fortes confluências do positivismo e do estruturalismo (PENNYCOOK, 1998), essa proposta de pedagogia como transgressão se concretiza no pressuposto de que não basta ensinar uma língua para fins comunicativos: é preciso considerar os efeitos/valores que essa língua produz na sociedade, refletindo sobre como nossos discursos colaboram com a perpetuação do preconceito e da discriminação contra as pessoas pobres, as pessoas negras, os(as) homossexuais, as mulheres, os povos indígenas etc. Ao fazêlo, estaremos não somente atravessando as fronteiras de um território proibido, mas também buscando novas formas de pensar a educação e o próprio ensino de LE/inglês, que muitas vezes se resume no exercício de atividades lúdicas e na transmissão de mensagens/informações triviais do(a) aluno(a) A para o(a) aluno(a) B (PENNYCOOK, 1998).

Partindo da ideia de que tanto a cultura quanto a aprendizagem de línguas ocorrem dentro das relações de poder, esse autor alega que, enquanto o ensino de línguas "continuar a trivializar-se, recusando-se a explorar aspectos políticos e culturais da aprendizagem de língua, ele estará mais vinculado à acomodação do que a qualquer noção de acesso ao poder" (PENNYCOOK, 1998, p. 27). Portanto, como professores(as) e/ou pesquisadores(as), devemos estar conscientes das "conexões entre o nosso trabalho e as questões mais amplas de desigualdade social", rompendo "com os modos de investigação que sejam associais, apolíticos e a-históricos" (p. 42-43).

Essas ideias nos fazem pensar em uma abordagem mais holística e politizada para o ensino de LE/inglês; uma abordagem que nos possibilite ensinar nossos(as) alunos(as) a transgredir as fronteiras da dominação por meio da língua-alvo (MOITA LOPES, 2003). Mas que tipo de ensino seria esse? Quais seriam as suas características, as suas bases epistemológicas e as suas consequências para a educação e para a sociedade como um todo? Tais perguntas me motivaram a 
escrever este texto e por meio dele compartilhar algumas reflexões sobre o ensino crítico de línguas, que, nas palavras de Ferreira (2006, p. 35), "relaciona-se com a forma como se ensina em sala de aula, seus objetivos, seu papel na sociedade e a habilidade de agir reflexivamente".

Na próxima seção, apresento os pressupostos teóricos que darão suporte às minhas reflexões. Em princípio, focalizo algumas características do ensino crítico de línguas. Posteriormente, exploro alguns aspectos básicos da Linguística Aplicada Crítica, uma frente da Linguística Aplicada que, segundo Pennycook (2001), visa estabelecer uma relação entre o campo da Linguística Aplicada - salas de aula, traduções, conversações, entrevistas e textos - e as questões mais amplas da sociedade, propiciando o surgimento de uma abordagem transgressiva para o ensino de LE/inglês.

\section{PRESSUPOSTOS TEÓRICOS}

Desde que comecei a trabalhar com o ensino crítico de LE/inglês, meu principal objetivo tem sido levar meus(minhas) alunos(as) a utilizar a língua-alvo para refletir sobre temas de caráter político-social, tais como classe, raça, etnia, gênero, sexualidade etc., assim como sugere Ferreira (2006) em sua perspectiva crítica e anti-racista para o ensino de línguas. Em alusão a Paulo Freire, a autora define o ensino crítico como uma pedagogia emancipatória que "possibilita o repensar o mundo de alunos e professores, de uma forma que faça o arranjo para uma ação transformadora e que possibilite a mudança social" (FERREIRA, 2006, p. 37).

No entanto, antes de promover essa "mudança", é preciso desvelar as diversas formas de preconceito e discriminação, bem como reconhecer o peso de suas adversidades em âmbito social. Muitas pessoas sabem, por exemplo, que o Brasil apresenta elevados índices de pobreza, mas poucas têm consciência de que a grande maioria das pessoas pobres, no Brasil, é negra (PINHEIRO et. al., 2008). Muitas sabem, também, que as mulheres não têm tido a mesma visibilidade que os homens no contexto brasileiro (PINHEIRO et. al., 2008), mas raros(as) são aqueles(as) que param para pensar em questões como: Por que precisamos de uma delegacia que assegure tranquilidade às mulheres? Outras pessoas, ainda, reconhecem a existência do preconceito contra homossexuais, travestis, transgêneros, transexuais etc., mas poucas admitem que assumir um gênero ou uma sexualidade "desviante" muitas vezes culmina na morte desses indivíduos considerados estranhos e anormais (BAHIA, 2010). 
Para Freire (2006), o(a) professor(a) deve considerar seus(suas) alunos(as) como seres que se movem no e com o mundo, participando diretamente das relações de poder que o sustentam. Assim sendo, acredito que esses(as) alunos(as) devem ser expostos(as) aos problemas sociais, pois, como afirma Louro (1997, p. 121), as desigualdades "só poderão ser percebidas - desestabilizadas e subvertidas - na medida em que estivermos atentas/os para suas formas de produção e reprodução". Ao discutir as contribuições dos Estudos/Pedagogias Feministas para a Educação, a autora alega que, se estamos dispostos(as) a problematizar, na escola, os binarismos rígidos que permeiam as relações de gênero,

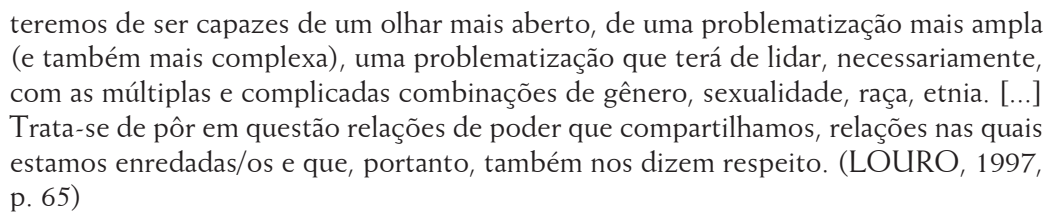

Nessa mesma linha de raciocínio, porém sob a ótica dos Estudos Culturais, Silva (2007) defende uma pedagogia que analise os mecanismos de produção da diferença e que aborde as possibilidades de contato com esse outro diferente. Todavia, não se trata apenas de "reconhecer e celebrar a diferença e a identidade, mas questioná-las", explorando, assim, "as possibilidades de perturbação, transgressão e subversão das identidades existentes". Como professores(as) atentos(as) à situação conflitiva na qual se inscrevem e se organizam as identidades, devemos estimular "o impensado e o arriscado, o inexplorado e o ambíguo, em vez do consensual e do assegurado, do conhecido e do assentado" (SILVA, p. 100). Em outras palavras, devemos educar para transgredir.

Com base nas reflexões de hooks (1994), poderíamos definir a transgressão como um ato de resistência e empoderamento. Valendo-se de sua própria experiência como aluna e professora negra nos Estados Unidos, a autora sugere que educar para transgredir significa abrir nossas mentes e corações para conhecer o que está além das fronteiras, além do que o sistema nos permite conhecer, de modo a pensar e repensar nossas próprias atitudes e valores sociais/educativos. Tal proposta se articula com a ideia de que a sala de aula é um espaço multicultural, composto por diferentes raças, costumes, credos, enfim, por diferentes histórias/experiências de vida, e que por isso devemos educar além do permitido para compreender melhor a dinâmica dessa diversidade cultural: devemos instigar o questionamento e por meio dele reconhecer as diversas formas de preconceito e discriminação que emergem das nossas práticas/ escolhas e das interações pedagógicas. Conforme hooks $(1994,2010)$, esse seria um 
meio de promovermos uma pedagogia transgressiva e descolonizadora, que envolva "trocas radicais construtivas no modo como ensinamos e aprendemos, assim com as mentes pautadas na liberdade ensinam para transgredir e transformar" (HOOKS, 2010, p. 28, grifo no original).

Essas parecem ser algumas das características que têm dado suporte às pesquisas em Linguística Aplicada Crítica, um campo de estudos em Linguística Aplicada que, de acordo com Pennycook (1998), propõe um rompimento com o positivismo e o estruturalismo, bases do pensamento iluminista europeu, como forma de explorar o caráter histórico, político e cultural da língua. Para o autor, na condição de professores(as) e/ou pesquisadores(as), "precisamos assumir posturas morais e críticas a fim de tentar melhorar e mudar um mundo estruturado na desigualdade" (PENNYCOOK, 1998, p. 39). Nesses termos, um dos principais desafios da Linguística Aplicada Crítica seria encontrar meios para "compreender a relação entre os conceitos de sociedade, ideologia, capitalismo global, colonialismo, educação, gênero, racismo, sexualidade, classe e as interações de sala de aula" (PENNYCOOK, 2001, p. 5). A título de exemplo, vejamos alguns dos interesses e aspectos centrais desse campo de estudos:

Quadro 1. Interesses e aspectos centrais da Linguística Aplicada Crítica (PENNYCCOK, 2001, versão adaptada)

\begin{tabular}{|c|c|}
\hline INTERESSES & ASPECTOS CENTRAIS \\
\hline Sólida visão da Linguística Aplicada & Interdisciplinaridade e autonomia \\
\hline Visão praxiológica & $\begin{array}{l}\text { Pensamento, desejo e ação integrados } \\
\text { como práxis }\end{array}$ \\
\hline Campo de trabalho crítico & Trabalho voltado para a transformação social \\
\hline Cobertura de relações micro e macro & $\begin{array}{l}\text { Relação dos aspectos da Linguística Aplicada com domínios sociais, } \\
\text { culturais e políticos mais amplos }\end{array}$ \\
\hline Questionamento social crítico & $\begin{array}{l}\text { Questões de acesso, poder, disparidade, desejo, diferença e } \\
\text { resistência }\end{array}$ \\
\hline Diálogo com a Teoria Crítica & $\begin{array}{l}\text { Questões de desigualdade, justiça, } \\
\text { direitos e compaixão }\end{array}$ \\
\hline Problematização de práticas naturalizadas & Constante problematização de práticas naturalizadas \\
\hline Autoquestionamento & Constante questionamento de seus próprios interesses e domínios \\
\hline
\end{tabular}

Como se pode perceber, a Linguística Aplicada Crítica pretende se engajar em um trabalho de ação política, tornando-se intrinsecamente crítica no sentido 
de ser politicamente comprometida e desafiadora (COOK, 2003). Todavia, faz-se necessário dizer que, no contexto de ensino e aprendizagem de LE/inglês, essa proposta de educação requer atitudes transgressivas por parte dos(as) professores(as), os(as) quais terão de derrubar as fronteiras disciplinares que separam o seu trabalho de questões sociais mais amplas (PENNYCOOK, 2006). A título de exemplo, será preciso refletir sobre as várias formas de manifestação da cultura, trazendo à tona a problemática da relação masculino-feminino, branco(a)-negro(a), heterossexualhomossexual, rico(a)-pobre, entre outras, pois é esse desvelamento/conflito que desencadeará no(a) aluno(a) um processo de reflexão sobre a "construção da subjetividade no mundo contemporâneo e permeado de tensões, especialmente quando se depara com assuntos considerados, até então, tabus" (SCHUMAHER, 2004, p. 107).

Vislumbrando as possibilidades de transgressão no campo da Linguística Aplicada Crítica, Pennycook (2006) afirma que é necessário compreendermos o papel do discurso na formação de um sujeito múltiplo e conflitante. Assim, recomenda-nos considerar as implicações das viradas linguística, somática e performativa na constituição do que ele denomina Linguística Aplicada Transgressiva:

\begin{abstract}
A virada somática nos permite refocalizar a corporeidade da diferença, ao passo que a virada performativa sugere que as identidades são formadas na performance lingüística e corporificada, em vez de ser pré-dada. Isso também fornece a base para considerar as línguas de uma perspectiva antifundacionalista, pela qual o uso da linguagem é um ato de identidade que possibilita a existência da língua. (PENNYCOOK, 2006, p. 86, grifo no original)
\end{abstract}

Devido a essas reflexões, hoje me considero parte de um grupo que busca trazer e problematizar questões referentes à língua(gem), ao corpo e à diversidade em sala de aula, "um espaço de cruzamento de culturas, fluido e complexo, atravessado por tensões e conflitos" (CANDAU, 2008, p. 15, grifo no original). Além disso, tenho procurado desmistificar a ideia de que o ensino de LE/inglês se reduz à aplicação de técnicas pré-concebidas (regras gramaticais) e à promoção de atividades lúdicas e comunicativas, pois, tal como Pennycook (1998), acredito que devemos procurar meios para subverter a trivialização da aprendizagem e dos(as) aprendizes de línguas. Para Contreras (2002), uma postura de questionamento se articula com a imagem dos(as) professores(as) como intelectuais críticos(as) e transformadores(as) (GIROUX, 1997): profissionais que educam "seus alunos como cidadãos críticos e ativos, compromissados com a construção de uma vida individual e pública digna de ser vivida, guiados pelos princípios de solidariedade e de esperança" (CONTRERAS, 2002, p. 161, grifos meus). 
Nessa perspectiva, embora haja professores(as) que definem o inglês como apenas mais uma língua que deve ser ensinada nos moldes da abordagem comunicativa de ensino de LE, alegando, por exemplo, que os(as) aprendizes, em sua maioria, não estão preocupados(as) em se tornar mais críticos(as) no decorrer de sua experiência de aprendizagem, é preciso considerar que essa mais uma língua não apenas descreve situações do dia-a-dia, mas produz e reproduz ações/valores na sociedade: ações/ valores que podem tanto manter quanto ressignificar e/ou desconstruir os discursos e práticas que promovem desigualdade e dependência (PENNYCOOK, 1998; MOITA LOPES, 2003). Em outras palavras, o falar está sempre ligado a um fazer (AUSTIN, 1975), e é nesse pressuposto que reside a ideia do ensino crítico de LE/ inglês como transgressão e prática de liberdade: uma abordagem contra-hegemônica que visa, por meio da língua(gem), pensar na construção de outros caminhos e de outras realidades possíveis para a Linguística Aplicada (MOITA LOPES, 2006).

A seguir, apresento uma breve descrição dos procedimentos metodológicos do estudo, na qual consta o tipo de pesquisa realizada, a natureza e a quantidade de participantes, os instrumentos utilizados para a coleta de dados e a perspectiva que será adotada na categoria subsequente.

\section{0 ESTUDO}

Este trabalho, que se caracteriza como um estudo qualitativo e de intervenção (LÜDKE e ANDRÉ, 1986), busca respaldo nos resultados de uma pesquisa que pretendeu analisar as características e as consequências do ensino crítico de língua inglesa no Centro de Línguas da UFG. Participaram dessa pesquisa os(as) alunos(as) de duas turmas, uma de Inglês 5, composta por 25 alunos(as), e uma turma de Inglês 8, composta por 18 alunos(as) - os(as) quais serão referidos(as), na próxima seção, por meio de codinomes; o professor-pesquisador, que ministrou aulas críticas, nas duas turmas, durante o segundo semestre letivo de 2008; e uma professora-observadora, que acompanhou as intervenções do professor-pesquisador ao longo do referido semestre. Os dados foram coletados por meio de sete questionários ${ }^{3}$ aplicados aos(às) alunos(as) (QAA), três sessões reflexivas - uma realizada com os(as) alunos(as) (SRA)

3. A título de descrição, foram aplicados os seguintes questionários: um questionário inicial, em agosto; cinco questionários de rotina/acompanhamento, no decorrer do semestre; e um questionário final, em novembro. Entretanto, por se tratar de um recorte da pesquisa em questão, optei por reunir os dados de todos os questionários em apenas um instrumento: 'questionários aplicados aos(às) alunos(as)' (QAA). 
e duas com a professora-observadora (SRPO) - e um diário de campo utilizado pelo professor-pesquisador (DCPP).

Com base na proposta de Pennycook $(1998$; 2001) e Ferreira (2006), as aulas críticas foram planejadas e conduzidas em torno de cinco temas principais: 1) O inglês na era da globalização; 2) A questão do corpo no mundo contemporâneo; 3) Raça e classe no Brasil ; 4) Cultura e identidade; e 5) Gênero e sexualidade. No entanto, foi necessário explorar alguns temas secundários na medida em que os(as) próprios(as) alunos(as) os traziam para as discussões. O quadro abaixo representa a distribuição de todos os temas abordados:

Quadro 2. Distribuição dos temas críticos abordados

\begin{tabular}{|c|c|c|}
\hline & TEMAS PRINCIPAIS & TEMAS SECUNDÁRIOS \\
\hline \multirow{2}{*}{ Agosto } & 0 inglês na era da globalização & $\begin{array}{l}\text { Imperialismo e capitalismo } \\
\text { A importância da educação } \\
\text { Aspectos da educação no Brasil }\end{array}$ \\
\hline & $\begin{array}{l}\text { A questão do corpo no mundo } \\
\text { contemporâneo }\end{array}$ & $\begin{array}{l}\text { Identidade de gênero } \\
\text { A construção social do belo } \\
\text { A importância da beleza }\end{array}$ \\
\hline Setembro & Raça e racismo no Brasil & $\begin{array}{l}\text { Ações afirmativas } \\
\text { A história do Brasil } \\
\text { Raça e racismo nos EUA }\end{array}$ \\
\hline Outubro & Cultura e identidade & $\begin{array}{l}\text { Diferenças culturais } \\
\text { Os povos indígenas no Brasil } \\
\text { Interculturalidade }\end{array}$ \\
\hline Novembro & Gênero e sexualidade & $\begin{array}{l}\text { Identidade } \\
\text { Religião e religiosidade } \\
\text { Novos modelos de família } \\
\text { O papel da educação } \\
\text { Estereótipos }\end{array}$ \\
\hline
\end{tabular}

Os dados da pesquisa serão explorados com base em perspectivas qualitativas de análise e interpretação. Haverá momentos, inclusive, em que as minhas reflexões serão apresentadas na forma de um relato de experiências e as falas dos(as) participantes serão colocadas em destaque para ilustrar essas reflexões e dialogar com as teorias anteriormente mencionadas, e não para comprovar hipóteses ou legitimar o estudo (DENZIN e LINCOLN, 2008). Em outros termos, o que me interessa não é validar os dados da pesquisa por meio de subsídios quantitativos (GUBA e LINCOLN, 2008), mas pensar em alternativas que os tornem capazes 
de esboçar, no contexto de ensino e aprendizagem de LE/inglês, "um futuro e um cenário alternativos da ação política", podendo "nos transpor do presente para o futuro" (RORTY, 1996, p. 227).

Trata-se, portanto, de um texto que visa transgredir o modelo hegemônico e disciplinar da escrita acadêmica e, assim, propor outras formas de pensar a produção de conhecimento em Linguística Aplicada, tal como sugere Moita Lopes (2006, p. 96) ao problematizar o papel desse campo de pesquisa no palco das mudanças paradigmáticas que vêm ocorrendo nas ciências sociais e nas humanidades em virtude do que ele denomina crise da ciência moderna. Conforme Lyotard (1984, 1988 apud FLYNN, 1996), essa seria uma maneira não apenas de ressignificar o que já foi feito, escrito e/ou pensado, mas também de resistir à ideia de que escrever academicamente significa abraçar um modelo que pressupõe a conversão dos objetos culturais dos textos em mercadorias inacessíveis ao grande público. Além disso, com base nas teorizações de Smith (1999), acredito que, ao transgredirmos a natureza hegemônica, disciplinar e colonial das metodologias ocidentais, estamos contribuindo com a descolonização do saber e abrindo espaço para o surgimento de novas formas de compreensão da realidade.

A seguir, apresento algumas reflexões sobre o meu trabalho com o ensino crítico de LE/inglês. Para tanto, busco respaldo nos dados concernentes às seguintes perguntas de pesquisa: Quais as características e as consequências do ensino crítico de LE/inglês no Centro de Línguas da UFG? Como o construto pedagogia como transgressão em Linguística Aplicada se articula com o ensino crítico de LE/inglês?

\section{REFLEXÕES SOBRE O ENSINO CRÍTICO DE LE/INGLÊS: A PEDAGOGIA COMO TRANSGRESSÃO}

Como já exposto, desde que comecei a trabalhar com o ensino crítico de LE/ inglês, o meu principal objetivo tem sido levar meus(minhas) alunos(as) a utilizar a língua-alvo para refletir sobre temas de caráter político-social, entre os quais raça, classe, gênero, sexualidade, educação, capitalismo, saberes subalternos etc. Ainda que essa abordagem possa ser implementada de várias formas ${ }^{4}$, a depender de uma

4. Há professores(as) que promovem aulas críticas por meio de discussões ou de pequenas intervenções; outros/as preferem trabalhar criticamente as atividades do próprio livro didático ou planejar atividades que envolvem a vida e a realidade social de seus(suas) alunos(as). O fato é que não há um modelo de 'ensino crítico' que possa ser implementado por todos(as) os(as) professores(as) de LE/inglês e em todos os contextos de ensino e aprendizagem. Trata-se de uma abordagem contextual. 
série de aspectos estruturais, ideológicos e políticos dos diferentes contextos de ensino e aprendizagem, minhas aulas críticas foram conduzidas por meio da leitura e da problematização de textos, vídeos e figuras ${ }^{5}$ relacionadas aos temas anteriormente citados.

Dentre as principais reflexões advindas dessa experiência está o fato de o ensino crítico de LE/inglês: ser uma abordagem mais próxima da realidade dos(as) alunos(as); desencadear discussões socialmente relevantes, colaborando com a ressignificação dos discursos e práticas hegemônicas vigentes; e permitir que os(as) alunos(as) se desenvolvam melhor linguístico e comunicativamente.

No que se refere à primeira característica, percebo que os(as) alunos(as), quando expostos(as) a temas críticos, apresentam duas reações: em um primeiro momento, eles(as) se assustam e se calam; em seguida, começam a tomar parte nas atividades. A primeira reação advém do choque com o novo, tendo em vista o fato de a maioria das aulas de LE em contextos brasileiros diversos se pautar, quase que essencialmente, no exercício de atividades lúdicas e comunicativas. A segunda reação, por sua vez, parece ocorrer quando os(as) alunos(as) percebem a relevância do enfoque de determinados temas em sala de aula e acabam se dando conta de que problematizar os conceitos de raça e classe no Brasil, por exemplo, é algo mais próximo de sua realidade do que descrever, comunicativamente, situações cotidianas envolvendo amigos(as), vizinhos(as) e parentes em geral. Em outras palavras, após um primeiro momento de estranheza, os(as) alunos(as) começam a perceber que sempre tiveram vontade de pensar e discutir esses temas. É como se apenas agora eles(as) tivessem a chance de expressar as suas ideias e por meio delas participar da vida social. Tais percepções podem ser observadas nas falas de alguns(algumas) deles(as):

As discussões eram de cunho social e político, diferentes dos semestres anteriores, que eram "alienadas", sobre temas fúteis. [...] a sala de aula é o local apropriado para essas discussões. (Heitor / Inglês 8 - QAA)

5. No Centro de Línguas, minhas aulas críticas eram ministradas na língua-alvo e eram conduzidas da seguinte forma: inicialmente, eu propunha uma atividade de aquecimento sobre o tema que seria abordado, seja por meio de figuras e/ou da formação de um mapa semântico no quadro; em seguida, promovia atividades colaborativas em torno de algum texto e/ou vídeo referente ao tema da aula; posteriormente, propunha um exercício de compreensão auditiva por meio de gravações em áudio e/ou de vídeos (debates, entrevistas, trechos de filmes etc); e, para finalizar, colocava no quadro alguns dos erros estruturais e fonéticos cometidos pelos(as) alunos(as) durante as discussões e pedia para que eles(as) os identificassem e os corrigissem. Essa última atividade era feita em pares e geralmente abria espaço para a revisão de vários tópicos gramaticais, os quais eram focalizados em aulas subsequentes. 
Concordo com essa visão de aprendizagem, de fazer a gente pensar [...] e de questionar nossos próprios valores. (Marco Aurélio / Inglês 5 - QAA)

Discutir assuntos que nos dizem respeito, que estão presentes em nosso dia-adia, sempre estimula e favorece a aprendizagem. Diálogos sobre esses temas nos envolvem muito mais do que fazer diálogos sobre vizinhos, pais e filhos ou sobre colegas de trabalho. (Marco Aurélio / Inglês 5 - QAA)

Esses temas [mais críticos] são bem diferentes dos que a gente já viu, porque dos outros [temas mais técnicos e convencionais], quando você vai falar, você meio que não tem que pensar, já fala meio automático. Agora, com esses temas [mais críticos], você tem sempre que estar ligado no que o outro está falando, na forma como você está falando e, paralelamente, [deve estar] pensando no que você vai falar. (Leonardo / Inglês 8 -SRA)

Como aponta Ferreira (2006), a problematização de temas críticos em aulas de línguas implica o desvelamento de práticas opressivas. Desse modo, somos convidados(as) a transcender os campos disciplinares de uma tradição que insiste em conceber o ensino de LE/inglês como um trabalho técnico, apolítico e distante dos conflitos sociais (PENNYCOOK, 1998). Em outros termos, somos convidados(as) a migrar de uma educação bancária para uma educação problematizadora, reconhecendo os(as) nossos(as) alunos(as) e a nós mesmos(as) como seres que se movem no e com o mundo e a sala de aula como um espaço de conflito e transformação da realidade (FREIRE, 2006). Entretanto, o problema que se apresenta é: Como esses temas críticos devem ser abordados?

Em princípio, defendo que o ensino crítico não pode dar margem a piadas e risos em sala de aula, pois, se o fizermos, correremos o risco de banalizar assuntos que devem ser abordados e problematizados com seriedade. A título de exemplo, como poderíamos refletir criticamente sobre a visibilidade da mulher negra e dos povos indígenas no Brasil por meio de piadas e/ou de atividades lúdicas? Talvez alguns(algumas) colegas argumentem que muitos(as) escritores(as) se valem do humor para abordar e problematizar situações como essa. Entretanto, não há como garantir que os(as) nossos(as) alunos(as) se valerão desse "humor crítico" para construir discursos alternativos e/ou contra-hegemônicos na língua-alvo (MOITA LOPES, 2003). Tal percepção se confirma, respectivamente, nas falas da professoraobservadora, do professor-pesquisador e do aluno Caio:

[...] falar de racismo é coisa séria. Se nós começarmos a fazer coisas muito dinâmicas, muito lúdicas... acho que a proposta de problematização se perde. (SRPO) 
[...] aí corremos o risco de banalizar uma coisa séria. Então, como é que eu faço pra chegar lá e mostrar que isso [um dado tema crítico] é uma coisa séria jogando figurinhas no chão pra montar, ou alguma coisa assim nesse estilo? Levar ao riso... isso eu não concordo, porque, como já foi dito, esse pode ser um caminho para a banalização de um assunto que precisa ser tratado com seriedade. (SRPO)

A questão de falar, de ser extremo, eu acho que esse é o ponto. Eu acho que por a gente não levar as coisas ao extremo é que fica tudo nessa brincadeira aí, porque as pessoas acabam analisando as coisas como brincadeira. Então, se não for extremista, vai ficar tudo na brincadeira. É por isso que a questão [do racismo] é velada e ninguém fica ciente da situação como ela é mesmo. (Inglês 5 - SRA)

Acredito que, devido a essa seriedade, vários(as) alunos(as) tenham começado a se interessar pelos temas críticos abordados. Com o passar do tempo, a resistência vai cedendo espaço à curiosidade, que tende a se tornar cada vez mais crítica e desalienada (FREIRE, 2006). Com base na discussão de Louro (1997), podemos inferir que, ao se perceberem como participantes das relações de poder, os(as) alunos(as) começam a se enxergar como possíveis agentes transformadores(as) dessas relações:

Foram importantes [as aulas críticas] não apenas na questão de aprender a língua, mas também de sermos culturalmente melhores e socialmente responsáveis. Essas discussões são importantes para diminuir o preconceito e pra gente conhecer ou esclarecer melhor esses conflitos sociais, [tais] como racismo, sexualidade e identidade. (Leonardo / Inglês 5 - QAA)

Apesar de envolver juízos e valores pessoais, esses temas devem ser discutidos em sala de aula; além disso, eles aumentam o interesse do aluno nas aulas e, consequentemente, a frequência de sua participação. (Heitor / Inglês 8-QAA)

Temas que nos façam refletir sobre nós mesmos e nossas relações com as outras pessoas e a sociedade como um todo levam-nos a retomar conceitos e a reavaliar as coisas em que acreditamos. (Marco Aurélio / Inglês 5-QAA)

Eu achei importante porque eu pelo menos tentei pensar no assunto, que como diz, são temas polêmicos que a gente não discute porque achamos que são indiscutíveis. Coisas que as pessoas acham que não tem como mudar. Poucas pessoas começam pelo menos a pensar no que pode ser feito pra mudar o racismo, por exemplo. (Pâmela / Inglês 5-SRA)

O mais gratificante, no entanto, é perceber que, no decorrer do semestre, alguns(algumas) alunos(as) começaram a levar os temas discutidos para os seus respectivos contextos, ultrapassando os limites do material didático e da própria 
sala de aula. Essa transcendência do espaço pedagógico remete à natureza transgressiva da educação (HOOKS, 1994) e, em especial, do ensino crítico de LE/inglês (FERREIRA, 2006; PENNYCOOK, 2006), o qual visa não somente tornar os(as) alunos(as) proficientes na língua-alvo, mas também explorar os aspectos políticos, ideológicos e culturais da aprendizagem de línguas (PENNYCOOK, 1998). Portanto, admite-se que, ao se moverem para além da sala de aula, os(as) alunos(as) estarão procurando novas oportunidades de reflexão e diálogo. Os dados abaixo confirmam essa percepção na medida em que demonstram como o tema racismo repercutiu na vida de duas alunas negras:

[...] acaba que isso está tão longe de você que você acaba não tendo o contato que deve pra poder pensar sobre isso. Mas não é também não! Isso está é próximo da gente e as pessoas não querem ver. Esses dias mesmo, dentro do ônibus, tinha uma menina rindo de um carinha negro que estava voltando pra casa todo sujo. Ela branquinha, do olho clarinho, rindo dele como se fosse a coisa mais engraçada do mundo, gozando, sabe? Eu fiquei assim... e fiquei encarando ela dentro do ônibus o tempo inteiro. Ela falando super alto e ele, todo humilde, ficou o tempo todo de cabeça baixa. E eu estava de costas pra ela e fiz questão de virar de frente e ficar encarando ela pra ver se ela se dava conta e ficava calada no canto dela. Mas eu fiquei grilada demais! (Amanda / Inglês 5 - SRA)

Igual teve a história daquele rapaz que foi assassinado, o Emmitt Till, que eu fui contar pro povo da faculdade. Aí o povo falava: "Não, mas hoje em dia isso não acontece mais não." E eu falava: "Gente, como não?!" Eu falava dos ônibus lá nos Estados Unidos, da separação, de ter lugar pra branco e negro. A gente estava até discutindo isso em Políticas Educacionais no Brasil [uma disciplina da grade dos cursos de Licenciatura] lá na faculdade mesmo [Biologia]... o povo acha que é invenção, que não existe racismo. O povo pensa que todo mundo é igual. E eu falei pra eles: "Mas eu estou estudando isso no Inglês uai!" Aí, uma colega perguntou: "Ah, mas por que você está tão indignada?" E eu falei: "Ué, eu estou vendo essas coisas no Inglês, que não é bem assim". Aí, essa colega falava que era isso, que essas coisas não acontecem e eu virei pra ela e falei: "É, mas você pensa assim porque você é branquinha". E então eu vi que as pessoas, elas vão tapando os olhos e acham que o racismo não existe. (Pâmela / Inglês 5 - SRA)

Até aqui pudemos observar que o ensino crítico de línguas suscita dúvidas ao questionar as normas e a sociedade, e é esse questionamento que abre espaço à crítica e à transgressão (HOOKS, 1994; FREIRE, 2006; PENNYCOOK, 2006). No entanto, de acordo com a professora-observadora, "isso não nos torna pessoas críticas em todos os instantes da vida, mas o questionamento vai abrir caminhos, vai deixar essa porta aberta" (SRPO). Assim sendo, penso que um dos principais 
objetivos do ensino crítico de línguas é suscitar a dúvida por meio do diálogo e da problematização das desigualdades sociais, e não exatamente converter ou convencer os(as) alunos(as) a acreditarem no que acreditamos ser politicamente correto. Nas palavras de Tadeu,

o papel do educador é bem maior que se prender ao seu conteúdo; é de transcender a sua área de atuação, de conhecimento, de ser curioso, de querer sempre aprender mais e adentrar outros campos do saber, em um processo transdisciplinar, como acredito que foi feito quando falamos sobre esses temas nas aulas de inglês. (Inglês 5 - QAA)

É preciso entender que a transdisciplinaridade demanda uma postura investigativa dos(as) professores(as). Dessa forma, é necessário estudar a fundo o que as outras pessoas estudam; é necessário entender de raça, de gênero, de sexualidade etc., tentando compreender como a língua(gem) opera na construção dessas categorias e, por conseguinte, no mascaramento das injustiças sociais (MOITA LOPES, 2006). Atuar criticamente significa lançar-se em um terreno de incertezas, visto que, a partir do momento em que sugerimos a problematização de temas críticos em sala de aula, os quais não estão diretamente ligados ao processo de aquisição/aprendizagem de LE/inglês, vários tipos de eventos críticos podem acontecer. E como devemos lidar com esses eventos que não estão prescritos no plano de aula? Vejamos, a seguir, o relato que o professor-pesquisador faz de uma aula sobre o tema Raça e Racismo no Brasil:

Outro evento crítico foi com o Edson, um aluno negro [Inglês 8], que, não sei por qual motivo, chegou no assunto de ações afirmativas nas universidade. E ele se mostrou totalmente contra. Ele ainda disse que nada tem que ser facilitado pro negro, que os negros têm que correr atrás mesmo, lutar, que eles não têm que ter cotas porque eles têm a mesma capacidade de lutar que os brancos. E falava tudo isso em inglês... a discussão foi toda em inglês. Mas a questão é que ele mesmo se contradizia. Ele começou a dizer que, na escola pública onde ele trabalha, existem mais negros que brancos. Quer dizer, ele mesmo vê que há uma disparidade aí que precisa de alguma forma ser reparada. Mas, mesmo assim, ele continua contra as cotas. Então, eu perguntei: "E você ainda acha que os negros têm as mesmas oportunidades que os brancos?" E ele continuou contra as cotas. Então, eu deixei quieto porque ele mesmo já tinha se contradito várias vezes. Na verdade, eu acho que ele não tem problema em se assumir negro, mas um [homem] negro que, durante a vida, construiu uma "identidade branca". [...] Ele não tem essa noção histórica do racismo e da história [da população negra] no Brasil. Talvez por isso ele cultive essa opinião que a grande maioria dos brasileiros faz questão de defender: que o racismo não existe aqui. (DCPP) 
Esse excerto mostra a tentativa de negociação entre duas opiniões: a do aluno, que é contra a política de cotas em universidades públicas, e a do professor, que é a favor. Como já mencionado, não é função de um(a) educador(a) crítico(a) tentar converter ou convencer os(as) seus(suas) alunos(as), mesmo porque toda forma de conhecimento pode ser opressiva (CONTRERAS, 2002). Entretanto, no caso de Edson, o que está em jogo não é a sua opinião a respeito da política de cotas, mas a negação do racismo no Brasil, o que, a meu ver, deve ser contestado, pois tratase de um equívoco. O racismo existe e causa sofrimento às pessoas, tornando-as vítimas do preconceito e da exclusão: essa é a verdade que se pode conferir, por exemplo, no Retrato das Desigualdades de Gênero e Raça no Brasil (PINHEIRO et. al., 2008).

Portanto, não basta apenas ouvir um(a) aluno(a) expressar a sua opinião: é preciso levá-lo(a) a repensar os seus valores, as suas crenças e as suas práticas em uma perspectiva mais crítica e transgressiva, que problematize os discursos dados como naturais na sociedade; é preciso levá-lo(a) a refletir sobre como esses valores, crenças e práticas se articulam com a manutenção do preconceito e da discriminação, muitas vezes contra si mesmo(a). Por esse motivo, defendo que é necessário nos prepararmos teoricamente para problematizar temas críticos em sala de aula, pois apenas assim teremos elementos para instigar os(as) nossos(as) alunos(as) a pensar e a repensar as suas próprias opiniões, bem como para romper com os campos disciplinares que nos separam de outras áreas do conhecimento e das lutas por emancipação social (MOITA LOPES, 2006).

Além desses aspectos de cunho metodológico, o que mais marcou a minha experiência com o ensino crítico de LE/inglês no Centro de Línguas da UFG foi o fato de alguns(algumas) colegas questionarem a relevância dessa abordagem para o desenvolvimento linguístico e comunicativo dos(as) aprendizes. O que parece é que a grande maioria dos(as) professores(as) entende por relevante o ensino que se baseia em uma espécie de pedagogia do resultado puramente linguístico e comunicativo. Embora não concorde que essa pedagogia seja o foco do ensino crítico de línguas (PENNYCOOK, 1998, 2001; MOITA LOPES, 2006; FERREIRA, 2006), considero importante mencionar que todos(as) os(as) alunos(as) alegaram, no final do semestre letivo, que as aulas críticas contribuíram para o seu desenvolvimento como aprendizes de LE/inglês. A seguir, destaco algumas de suas considerações a esse respeito:

[...] sem perceber, a minha capacidade de ouvir, entender e falar em inglês aumentou muito. É como se algo muito complexo fosse ficando mais simples. (Fernando / Inglês 5 - QAA) 
As discussões fizeram a gente falar mais e os textos trouxeram um vasto vocabulário novo para utilizar na fala. (Márcio / Inglês 8 - QAA)

O mais interessante é que agora discuto temas mais sérios em inglês. Mesmo falando pouco, não tem sido um fardo como antes falar inglês em público. (Amanda / Inglês 5 - QAA)

Essas discussões são muito importantes, pois passo a refletir e discutir o tema na língua inglesa, acrescentando assim novas palavras e praticando as estruturas que eu já conheço. (Caio / Inglês 5-QAA)

Penso que, ao discutir temas críticos, as habilidades de argumentação são mais trabalhadas. (Rogério / Inglês 8 - QAA)

Nem se compara meu desenvolvimento! Eu não falava nada, ficava só resolvendo aqueles exercícios que todo mundo consegue decorando as estruturas [...] Hoje, eu falo pelos cotovelos, as pessoas me entendem e eu pratiquei a gramática de uma forma menos mecânica. (Amanda / Inglês 5 - SRA)

Essas falas mostram que a abordagem crítica não pretende transformar a aula de LE/inglês em aula de sociologia - como se tem argumentado em algumas ocasiões -, visto que os(as) próprios(as) alunos(as) afirmam ter se desenvolvido melhor linguístico e comunicativamente por meio dela. Desse modo, percebe-se que o ensino crítico nos permite ensinar os(as) nossos(as) alunos(as) a refletir sobre as relações de poder vigentes, transgredindo as fronteiras da dominação, como sugere hooks (1994), e, ao mesmo tempo, a se tornarem proficientes na língua-alvo. A diferença é que essa proficiência não caminha solitária, como acontece em outras abordagens que visam pura e simplesmente à transmissão de mensagens do(a) aluno(a) A para o(a) aluno(a) B (PENNYCOOK, 1998). No ensino crítico, ser proficiente na língua-alvo significa pensar criticamente por meio dela, tendo, portanto, consciência dos efeitos que seus enunciados podem produzir na sociedade mais ampla: os(as) alunos(as) se tornam conscientes do uso do verbo to be, mas também se tornam conscientes do poder de ação desse verbo sobre o mundo; aprendem que a forma correta de conjugação para o pronome she é is, mas também aprendem que, ao dizer she is ugly because she is black ou I don't like ber because she is a lesbian, eles(as) estão reiterando o preconceito e a discriminação contra as mulheres negras e os(as) homossexuais, respectivamente. 


\section{CONSIDERAÇÕES FINAIS}

Como pudemos observar, os dados e as reflexões anteriormente apresentadas mostram que o ensino crítico de línguas é uma abordagem transgressiva que demanda compromisso social e atitude investigativa. Por esse motivo, defendo que, antes de colocá-lo em prática, os(as) professores(as) devem se preparar teoricamente, tanto no que se refere aos pressupostos da Pedagogia Crítica e da Linguística Aplicada Crítica quanto aos temas que eles(as) pretendem trabalhar em suas aulas. Acredito que basear-se em um texto qualquer da internet não é suficiente para lidar com os eventos críticos de sala de aula, bem como para levar os(as) alunos(as) a refletir criticamente, na língua-alvo, sobre os mecanismos de produção e reprodução das desigualdades sociais. Portanto, não basta concordar com o ensino crítico: é preciso reconhecê-lo como necessário e mais próximo de uma realidade que, na condição de intelectuais críticos(as) (GIROUX, 1997), temos a obrigação de transformar. Afinal, se o mundo se descortina em língua(gem), é fato que pela língua(gem) esse mesmo mundo e a própria cultura podem ser reconstruídos (BENVENISTE, 1991).

Assim sendo, podemos concluir, ainda, que o ensino crítico de línguas é uma abordagem que contribui significativamente para a formação crítica de professores(as) (GIROUX, 1997; CONTRERAS, 2002), visto que demanda leituras e reflexões que lhes possibilitam não somente elaborar e conduzir aulas críticas, mas também reconhecer a dinâmica das relações de poder que operam na sala de aula de LE/inglês e na sociedade como um todo. Em outras palavras, ao preparar aulas críticas, os(as) professores(as) são convidados(as) a refletir criticamente sobre as diferenças e desigualdades sociais, e são essas reflexões, a meu ver, que lhes possibilitarão transgredir os limites normais da pedagogia (PENNYCOOK, 2006) e, de tal modo, produzir "cidadãos autônomos, e não subservientes, para que assim possam colaborar no processo de promoção de igualdade e justiça social" (FERREIRA, 2006, p. 45).

No entanto, como alega Rajagopalan (2003, p. 111, grifos no original), devemos estar cientes de que, ao estimularmos a crítica e o "constante questionamento das certezas que, com o passar o tempo, adquirem a aura e a intocabilidade dos dogmas", estaremos atraindo a ira daqueles(as) que estão plenamente satisfeitos(as) "com o status quo e interpretam qualquer forma de questionamento das regras do jogo estabelecidas como uma grave ameaça a si e à sua situação confortável e privilegiada". Enfim, "o educador crítico sempre foi e sempre será uma ameaça para os poderes constituídos". 
$\mathrm{Eu}$, particularmente, decidi comprar essa "briga", mas não porque o ensino crítico seja uma espécie de salvação para o ensino de LE/inglês, pois, como qualquer outra abordagem, ele também possui as suas limitações, os seus pontos altos e baixos. Na verdade, decidi comprar essa "briga" por dois outros motivos. Em primeiro lugar, o fiz porque ensinar inglês criticamente significa me valer da lingua do opressor (HOOKS, 1994) para problematizar assuntos referentes aos grupos marginalizados da sociedade. Desse modo, acredito estar promovendo, ainda que aos poucos e timidamente, o que Ghai (2003) denomina de estratégias contrabegemônicas na era da globalização: um quadro de direitos econômicos, sociais e culturais que enfatiza os problemas das vítimas da desigualdade e da opressão. Em segundo lugar, o fiz porque, na posição de um homem branco e de classe média que trabalha com linguagem e educação, a saber, dois dos aspectos mais essencialmente políticos da vida (PENNYCOOK, 1998), não posso me guiar pelas promessas de uma educação que se fundamenta na referida pedagogia do resultado puramente linguístico e comunicativo. Ao contrário, devo promover uma educação pós-estruturalista, pós-moderna e póscolonial, que, na tentativa de cumprir com o seu papel no combate às opressões, questiona, critica, dialoga e transgride as fronteiras hegemônicas e disciplinares da pedagogia e do conhecimento.

No que se refere aos olhares insatisfeitos mencionados por Rajagopalan (2003), tenho aprendido a conviver pacificamente com eles, pois também fazem parte da ciência e da diversidade. Entretanto, jamais deixarei de exercer minhas funções como educador, por mais que me peçam todos os dias para fazê-lo. Afinal, "somos mais autênticos/as quanto mais nos parecemos com aquilo que sonhamos para nós mesmos/as". Essa fala da personagem Agrado, do filme Tudo Sobre Minha Mãe, de Pedro Almodóvar, alude à imagem do homem que eu sempre quis ser: um professor que ensina para transformar. E é nessa zona de conflito que reside a minha autenticidade, a minha transgressão, pois, como alega hooks (1994), ao nos movermos para além das fronteiras, imaginando caminhos para subverter a ordem hegemônica das práticas sociais e educativas, estamos promovendo uma educação como prática de liberdade.

O desafio que se apresenta agora é investigarmos como essa abordagem pode ser implementada no ensino de inglês e espanhol das escolas regulares brasileiras, públicas e privadas, que são onde milhares de alunos(as) estão se formando não somente para o mercado de trabalho, mas para a vida em sociedade. Aliás, talvez esse seja um dos maiores desafios da Linguística Aplicada no século XXI: (re) descobrir o lugar das aulas e dos(as) professores(as) de LE na construção de um mundo mais democrático e livre. 


\section{REFERÊNCIAS BIBLIOGRÁFICAS}

AUSTIN, J. L. (1975) How to do things with words. 2a ed. Cambridge: Harvard University Press.

BAHIA, R. S. (2010) Relatório anual divulga números de bomossexuais assassinados no Brasil em 2009. Salvador: Grupo Gay da Bahia. Disponível em: <http://www.ggb.org.br/dossier\%20de\%20 assassinatos\%20de\%20homossexuais\%20em\%202009.html>. Acesso em: 15 setembro 2010.

BENVENISTE, E. (1991) Problemas de linguiistica geral I. Trad. Maria da Glória Novak e Maria Luiza Néri. 3a ed. Campinas: Pontes.

CANDAU, V. M. (2008) Milticulturalismo e educação: desafios para a prática pedagógica. In: CANDAU, V. M. (org.) Multiculturalismo: diferenças culturais e práticas pedagógicas. Petrópolis: Vozes, p. 13-37.

CONTRERAS, J. (2002) A autonomia de professores. Trad. Sandra Trabucco Valenzuela. São Paulo: Cortez.

COOK, G. (2003) Applied linguistics. Oxford: Oxford University Press.

DENZIN, N. K.; LINCOLN, Y. S. (2008) Introduction: the discipline and practice of qualitative research. In: DENZIN, N. K.; LINCOLN, Y. S. (org.) The landscape of qualitative research. Thousand Oaks: Sage Publications, p. 1-44.

FERREIRA, A. J. (2006) Formação de professores: raça/etnia. Cascavel: Coluna do Saber.

FLYNM, E. A. (1996) Writing as resistance. In: JAC: rbetoric, writing, culture, politics. v. 16, n. 1, p. 1-4. Disponível em: <http://www.jacweb.org/Archived_volumes/Text_articles/V16_I1_Flynn. htm >. Acesso em: 25 out. 2010.

FREIRE, P. (2006) Pedagogia do oprimido. 45a ed. Rio de Janeiro: Paz e Terra.

GHAI, Y. (2003) Globalização, multiculturalismo e direito. In: SANTOS, B. S. (org.) Reconbecer para libertar: os caminhos do cosmopolitismo multicultural. Rio de Janeiro: Civilização Brasileira, p. 555-613.

GIROUX, H. A. (1997) Os professores como intelectuais: rumo a uma pedagogia crítica da aprendizagem. Trad. Daniel Bueno. Porto Alegre: Artes Médicas.

GUBA, G. G.; LINCOLN, Y. S. (2008) Paradigmatic controversies, contradictions, and emerging confluences. In: DENZIN, N. K.; LINCOLN, Y. S. (org.) The landscape of qualitative research. Thousand Oaks: Sage Publications, p. 255-286.

HOOKS, B. (1994) Teaching to transgress: education as the practice of freedom. New York: Routledge.

LOURO, G. L. (1997) Gênero, sexualidade e educação: uma perspectiva pós-estruturalista. Petrópolis: Vozes.

LUDKE, M.; ANDRÉ, M. E. D. A. (1986) Pesquisa em educação: abordagens qualitativas. São Paulo: EPU.

MOITA LOPES, L. P. (2003) A nova ordem mundial, os parâmetros curriculares nacionais e o ensino de inglês no Brasil: a base intelectual para uma ação política. In: BARBARA, L.; RAMOS, R. C. G. (org.). Reflexão e ações no ensino-aprendizagem de línguas. São Paulo: Mercado de Letras, p. 29-57.

(2006) Linguística Aplicada e vida contemporânea: problematização dos construtos que têm orientado a pesquisa. In: MOITA LOPES, L. P. (org.) Por uma Linguística Aplicada Indisciplinar. São Paulo: Parábola Editorial, p. 85-107.

PENNYCOOK, A. (1998) A lingüística aplicada dos anos 90: em defesa de uma abordagem crítica. In: SIGNORINI, I; CAVALCANTI, M. C. (org.). Lingüística aplicada e transdisciplinaridade. Campinas: Mercado de Letras, p. 23-49.

. (2001) Critical Applied Linguistics: a critical introduction. Mahwah, NJ: Lawrence Erlbaum Associates. 
PENNYCOOK, A. (2006) Uma lingüística aplicada transgressiva. In: MOITA LOPES, L. P. (org.). Por uma linguística aplicada indisciplinar. São Paulo: Parábola, p. 67-84.

PINHEIRO, L. et. al. (2008) Retrato das desigualdades de gênero e raça. Brasília: Ipea; SPM; UNIFEM.

RAJAGOPALAN, K. (2003) Por uma Lingüística Crítica: linguagem, identidade, e a questão ética. São Paulo: Parábola Editorial.

RORTY, R. (1996) Feminismo, ideologia e desconstrução: uma visão pragmática. In: ŽIŽEK, S. (org.) Um mapa da ideologia. Rio de Janeiro: Contraponto, p. 227-234.

SCHUMAHER, S. (2004) Uma escola que educa cidadãos e cidadãs. In: GONÇALVES, E. (org.) Desigualdades de gênero no Brasil: reflexões e experiências. Goiânia: Grupo Transas do Corpo, p. $105-$ 110.

SILVA, T. T. (2007) A produção social da identidade e da diferença. In: SILVA, T. T. (org.) Identidade e diferença: a perspectiva dos Estudos Culturais. Petrópolis: Vozes, p. 73-102.

SMITH, L. T. (1999) Decolonizing methodologies: research and indigenous peoples. London: Zeb Books.

Recebido: 23/03/2011

Aceito: 4/11/2011 
